\title{
Tique e toc na escola: mais que um problema de saúde, uma questão social e pedagógica
}

\author{
Tic and toc in school: more than a health problem, a social and educational matter
}

Tic y toc en la escuela: más que un problema de salud, un asunto social y educativo

WALNER MAMEDE*

\begin{abstract}
$\longrightarrow$ »
\section{RESUMO}

O transtorno do tique é um problema que envolve eventos tônicos ou clônicos corporais ou vocais, que vai além de uma abordagem patológica, em direção a uma necessária abordagem social e educacional. Sua ocorrência pode estar ou não associada com distúrbios psicológicos, caracterizando um transtorno mais complexo denominado Síndrome de Tourette. Em qualquer caso tratado, ele se constitui como um problema a ser enfrentado na escola, seja na perspectiva da aprendizagem, seja na da socialização. Por meio de uma incursão na literatura disponível sobre o tema, o presente artigo tem como principal objetivo a apresentação desse mal, tão pouco conhecido entre os profissionais da Educação, esclarecendo seus sintomas e hipóteses etiológicas e sugerindo estratégias e direções que podem mitigar o sofrimento do aluno em seu processo de escolarização.
\end{abstract}

Palavras-chave: Doença dos Tiques. Síndrome de Tourette. Transtorno Obsessivo-Compulsivo. Educação Inclusiva.

\begin{abstract}
The tic's disorder is a trouble involved with body and vocal occurrences, requiring a social and educational approach. It can be associated with psychological disorders and characterize a disease called Tourette Syndrome that is a school problem both as learning as socialization. Through of literature consulted, this paper has as aim main the presentation of this disease, few known into education, showing its symptoms and hypotheses and suggesting forms to reduce the student's suffering in your scholar process.
\end{abstract}

Keywords: Tic's Disease. Tourette Syndrome. Obsessive-Compulsive Disorder. Inclusive Education.

\section{RESUMEN}

Trastorno del tic es un problema involucrado con ocurrencias corporales y vocales, lo que requiere un enfoque social y educativo. Puede estar asociado con trastornos psicológicos y caracterizar una enfermedad llamada síndrome de Tourette que es un problema de la escuela tanto para el aprendizaje y para la socialización. A través de la literatura consultada, este documento tiene como objetivo principal presentar esta enfermedad, poco conocida en la educación, mostrando sus síntomas e hipótesis, y sugerir formas para reducir el sufrimiento del estudiante en su proceso académico.

Palabras clave: Enfermedad de Tics. Síndrome de Tourette. Desorden Obsesivo-Compulsiva. Educación Inclusiva.

\footnotetext{
* Doutor em Ensino na Saúde pela Universidade de Brasília; Coordenação Geral de Monit. e Aval. de Resultados (CGMR) da Coordenação de Aperfeiçoamento de Pessoal de Nível Superior (Capes), Brasília/DF-Brasil.E-mail: <walner.mamede@capes.gov.br; walnermamede@gmail.com>.
} 
Muitos de nós já vimos ou ouvimos falar de pessoas que possuem os famosos tics ou tiques nervosos (Doença dos Tiques-DT). Eles se apresentam de várias formas, por movimentos corporais ou emissões sonoras repetitivas involuntárias ou voluntárias, neste último caso, em resposta a uma necessidade sensorial involuntária sensação premonitória ou de urgência cinestésica -, aparecendo antes dos 18-21 anos (comumente, entre os $6 \mathrm{e}$ os 9 anos, mas podendo ocorrer antes), modificando-se em tipo, localização, intensidade, complexidade e número ao longo da vida, intensificando-se na puberdade e tendendo a uma atenuação na fase adulta. Quando tais tiques possuem associação de um sintoma fônico com sintomas motores e, normalmente, distúrbios psicológicos (fobias, obsessões, compulsões, dificuldades de aprendizagem, déficit de atenção, hiperatividade...), obtemos ${ }^{1}$ a caracterização de uma patologia mais complexa denominada Síndrome de La Tourette (ST). A ausência dessa associação descarta o diagnóstico da ST, definindo o acometimento apenas como Doença dos Tiques (tiques transitórios, crônicos ou inespecíficos), especialmente se é secundária a outro mal ou se seu curso não durou mais que três meses, por pelo menos um ano, sem intervalos maiores que 90 dias consecutivos (MATOS e MATOS, 1999; LOUREIRO et al., 2005; GERMINIANI et al., 2012). Entretanto, um ponto de divisão clara entre DT e ST, especialmente se há associação de tiques motores e fônicos, é problemático se considerarmos que os distúrbios psicológicos (um elemento diferencial entre ambos) podem estar presentes em diferentes graus de intensidade, indo desde uma mania corriqueira, como o fetiche por certos objetos, até uma obsessão severa, como a necessidade de se proteger contra germes, passando por pequenos medos, como a ansiedade em lugares altos, ou grandes fobias, como o pavor paralisante da altura. Tal dificuldade está implícita ao compararmos documentos oficiais como o DSM-IV, o CID-10 e o manual da Tourette Sindrome Association, nos Estados Unidos, o que sugere a existência de um continuum entre ambos os transtornos, assim como ocorre com o espectro obsessivo-compulsivo (HOUNIE e PETRIBÚ, 1999).

A primeira pessoa a identificar, patologicamente, a ST, até então denominada doença da criança selvagem e maldição dos tiques e que, hoje, acomete de 1-3\% da população mundial, foi o médico Jean Marc Gaspard Itard, em 1825, a partir dos acometimentos sofridos pela Marquesa de Dampierre. A partir daí, outros dois médicos descreveram acometimentos semelhantes: Trousseau, em 1873, e George Beard, em 1881. Mas foram os trabalhos

\footnotetext{
1 Por uma postura política e conceitual em relação a um específico modelo de Ciência, no qual a impessoalidade não possui primazia, neste texto optamos em apresentar a flexão verbal em primeira pessoa do plural.
}

do neurologista francês Georges Gilles de La Tourette, ainda aluno no Hospital de la Salpêtrière, em $1885^{2}$, que deram visibilidade e nome para a doença ao ser descrita de forma ampla e pormenorizada, correlacionando aspectos, até então, abordados isoladamente por seus antecessores. A ST é 3-4 vezes mais comum no sexo masculino, podendo estar relacionada com altos níveis de testosterona cerebral, sendo seus sintomas exacerbados por situações de tensão e atenuados por relaxamento, febre, orgasmo ou situações que demandam concentração. As tentativas de sua repressão pela vontade são seguidas de exacerbação rebote dos tiques (SANZ, 1994; HOUNIE e PETRIBÚ, 1999; MATOS e MATOS, 1999; LOUREIRO et al., 2005; RAMALHO et al., 2008; PAULO, 2010; GERMINIANI et al., 2012).

No caso da ST, outras síndromes podem se manifestar de forma associada (comorbidade), como o Transtorno Obsessivo-Compulsivo (TOC), inclusive por meio das chamadas fobias, ou o Transtorno do Déficit de Atenção e Hiperatividade (TDAH), no qual o indivíduo pode apresentar um quadro com um ou mais dos seguintes sintomas: distração crônica, impulsividade reativa, esquecimento de responsabilidades, desvio de atenção, diversidade de interesses simultâneos, descontrole cronológico, indisciplina, resistência contra a autoridade, dificuldades na obediência de regras, surtos de raiva, sono perturbado, desordens afetivo-emocionais e do humor e dificuldades de adaptação social, com tendências à baixa autoestima, frustração, depressão, drogadição e suicídio. Nos casos mais graves, a ST está associada, ainda, com problemas de aprendizagem relacionados a dificuldades de compreensão e produção da linguagem, de memorização e de percepção visual, à existência de dislexia, disgrafia, dispraxia e disfluência discursiva e a um sentimento latente de rejeição pelos pares. Algumas complicações podem surgir, como descolamento da retina, problemas ortopédicos e acometimentos cutâneos, entre outros, como resultado direto ou indireto dos episódios tônicoclônicos (HOUNIE e PETRIBÚ, 1999; LOUREIRO et al., 2005; PAULO, 2010; REINHARDT e REINHARDT, 2013).

Vista na perspectiva da Educação, a ST ou mesmo a DT vão além de um problema de saúde e se tornam um problema social. Na medida em que seus sintomas comprometem uma aprendizagem e uma socialização possíveis do indivíduo, há que ser tratada como um elemento perturbador da pretensa homogeneidade escolar, em direção à sua compreensão como mais um item na já tão diversa realidade da sala de aula. Para isso, não basta discutirmos um processo de Educação Especial, o

\footnotetext{
2 Alguns estabelecem essa data como 1884 (HOUNIE e PETRIBÚ, 1999; LOUREIRO et al., 2005)
} 
qual tende a sustentar a prática pedagógica por meio dos diagnósticos e orientações médicas sobre a incapacidade do aluno, em um atendimento tão personalizado que se torna excludente, na medida em que exige do indivíduo que se ajuste ao sistema, sem o esforço deste para sua inclusão, em nome de um padrão de normalidade. Devemos sim, adentrar o espectro da Educação Inclusiva, que busca compreender todos os alunos e cada um deles como parte da diversidade humana e merecedores de atenção especial, cada um em sua especificidade em um contexto social, e no qual o professor possui outro papel que não aquele demandado pelas abordagens tradicionais da Educação, a que Paulo Freire (1987) tão bem denominou de educação bancária. Nesse sentido, tornasse necessário que o professor ou qualquer profissional que vá lidar com o indivíduo acometido por tiques (ST ou não) seja conhecedor desse problema, para que bem estruture seu fazer e atenda à especificidade que o indivíduo demanda. Assim, com esse objetivo em mente, tem-se o presente artigo, que se ocupa de realizar uma revisão bibliográfica e de estabelecer algumas relações entre a ST e o TOC, passando pela Doença do Tique e propondo certas interconexões com a sala de aula, sem se ocupar da discussão sobre a TDAH, uma vez que esta vem sendo já mais amplamente debatida, tendo por enfoque os processos educativos.

\section{TIQUES, UM TOQUE A MAIS SOBRE O ASSUNTO}

Os tiques podem ser simples (apenas um grupo muscular) ou complexos (associação de grupos musculares) e, geralmente, iniciam-se nos ombros ou na cabeça, com piscadelas, espasmos faciais, volteio dos olhos e contorções da língua, evoluindo para movimentos associados, como contrações ou extensões de segmentos corporais, pisada estereotipada, inclinação do corpo, pulos, chutes, agachamentos, ajustes da roupa, toques ou arremessos de coisas, autoagressão; e para emissões sonoras na forma de escarros, arrotos, grunhidos, gemidos, assovios, fungação ou gritos e frases inteiras de conteúdo religioso, obsceno e escatológico (coprolalia), autorrepetição vocal (palilalia) ou imitações vocais (ecolalia), imitações motoras (ecocinese e ecopraxia), gestos obscenos (copropraxia) e uso aleatório, repetitivo e descontextualizado de palavras em frases. Além disso, na ST, sintomas como convulsões, distúrbios comportamentais e descoordenação ou agitação motoras podem estar presentes (MERCADANTE et al., 2004; RAMALHO et al., 2008).

A sintomatologia dos tiques, especialmente a ST, que nos últimos anos sofreu considerável aumento de incidência e do interesse em sua pesquisa, possui um currículo interessante e uma grande imprecisão conceitual, sendo, em geral, considerada como uma disfunção relacionada a elementos do sistema nervoso central e que se traduz em eventos físicos corporais e comportamentais, cuja perpetuação parece ser hereditária (SANZ, 1994; VÁZQUEZ-PALÁCIOS e BONILLAJAIME, 2004; LOUREIRO et al., 2005; FERRARO, RIBEIRO e CAVALHEIRO, 2008; RAMALHO et al. 2008). Primeiramente, como qualquer outra deficiência à época, a presença de tiques foi considerada um indicador de possessão demoníaca, ainda durante a Idade Média. Em 1486, com o apoio do Papa Inocencius VIII, uma espécie de manual de caça às bruxas, de nome Malleus Maleficarum, foi publicado e nele havia o relato da história de um padre que, ao se ajoelhar em frente à imagem da Virgem Maria, começava a movimentar a língua, emitindo sons e blasfêmias de forma incontrolável. Outro caso era o de uma mulher que blasfemou compulsivamente durante as bênçãos de uma missa. Ambos os casos foram encaminhados para o exorcismo e, dada a ineficácia deste, depois para a fogueira, pela Inquisição. Não por acaso, a personagem central do filme $O$ Exorcista, encarnada por Linda Blair, possuía comportamento que lembrava os sintomas da ST. Ela parece ter sido baseada nos sintomas bizarros de uma paciente que adentrou o hospital da Georgetown University, em 1974, e foi tratada como portadora da ST (PAULO, 2010; GERMINIANI et al., 2012).

Já em 1921, a sintomatologia do tique, particularmente a ST, passou a ser encarada como uma desordem neuropsiquiátrica, pela Psicanálise, que a tratou como uma rota alternativa, uma válvula de escape para pessoas que possuíam o desejo sexual exacerbado, mas, reprimidas sexualmente, não podiam exercê-lo, o que se manifestava, em alguns casos, como o onanismo, em outros, como tiques nervosos. Em 1998, surgiu uma hipótese (imunológica) de que a manifestação de tiques teria relação com alterações imunes e com a infecção por uma bactéria chamada Streptococcus, a qual interferiria com a ação da dopamina no sistema nervoso central (SNC). Essa hipótese ganhou um apelidinho curioso Pandas (Pediatric Autoimmune Neuropsychiatric Disorders Associated with Streptococcus) e tem sua origem na descrição de maior prevalência de tiques e TOC em crianças com Coreia de Sydenham, mas hoje é pouco considerada, por ausência de corroboração empírica significativa. E duas outras hipóteses têm recebido maior atenção dos pesquisadores. A genética (algo já ventilado pelo próprio Gilles de La Tourette, ao afirmar que havia um componente hereditário na doença), que, desde a década de 1970, tem se aprimorado e, recentemente, demonstrou que, em transmissões maternas, há mais frequência de tiques motores complexos e, em transmissões paternas, 
há maior frequência de tiques fônicos (cujo aparecimento é precoce) e maior proeminência de TDAH. E a hipótese neuroquímica, que, tendo sido proposta na década de 1960, estabelece uma relação da ST com uma exacerbação das ações da dopamina e da noradrenalina e com uma redução da ação da serotonina no SNC. Eventos de estresse pré ou pós-parto de diversas naturezas, inclusive a hipóxia, têm sido também considerados como desencadeadores dessa doença (HOUNIE e PETRIBÚ, 1999; MATOS e MATOS, 1999; LOUREIRO et al., 2005; DIAS et al., 2008; GERMINIANI et al., 2012).

Uma das hipóteses consideradas, atualmente, é a de que alterações no circuito motor seriam responsáveis pela etiologia dos tiques. Em uma pessoa sem o acometimento, estímulos nervosos advindos de uma região cerebral denominada tálamo são inibidos por outra região denominada corpo estriado para que o córtex cerebral não permaneça, continuamente, estimulado e não surjam eventos motores e fônicos compulsivos. Isso não ocorre em uma pessoa acometida pela sintomatologia dos tiques. As drogas com maior eficácia no tratamento dos tiques são os neurolépticos (haloperidol, pimozida), mas outras, com menor impacto colateral, como os antagonistas da serotononina (sertralina, fluoxetina), e os agonistas alfaadrenérgicos (clonidina, guanfacina), têm sido utilizados, assim como risperidona, nicotina, benzodiazepínicos e toxina botulínica, em casos refratários. Com o avanço dos estudos, identificou-se, também, a presença de tiques não genéticos, chamados touretismo, decorrentes do uso de neurolépticos, de intoxicações por monóxido de carbono, de traumatismo craniano, de encefalites virais, do abuso de cocaína ou da retirada de opiáceos, entre outras, e de síndromes tic-like, comportamentos semelhantes à DT, mas precedidos por obsessões. Esta, uma situação que talvez possa explicar a resposta do padre em frente à Virgem Maria e da mulher na benção da missa. Outras patologias, como a Doença de Wilson, a Doença de Huntington, a Coreia de Syndenham e a Doença de Hallervorden-Spatz, apresentam tiques ou movimentos semelhantes como sintomas e precisam ser descartadas no diagnóstico da DT/ST. Ainda que os estudos tenham avançado bastante, não se tem clareza, até os dias atuais, sobre as causas da DT/ST ou sobre como tratá-las de forma eficiente. Assim como é nebulosa a separação entre as duas, fazendo mais sentido sua abordagem por meio de um espectro, no qual ambas são consideradas como parte de um continuum, junto com as manifestações que as acompanham, como as desordens comportamentais, descoordenação motora, fobias, obsessões e outras (MATOS e MATOS, 1999; ROSÁRIO-CAMPOS e MERCADANTE, 2000; MERCADANTE et al., 2004; LOUREIRO et al., 2005; GERMINIANI et al., 2012).

\section{TIQUE E TOC: UMA CACOFONIA ALÉM DO SOM}

A obsessão se caracteriza como um evento mental recorrente, invasivo e perturbador desencadeado por ideias ou estímulos sensoriais que motivam atos físicos ou mentais repetitivos e irresistíveis, destinados ao alívio da tensão e do incômodo obsessivo, aos quais se denomina compulsão. Até $15 \%$ dos indivíduos com TOC apresentam ocorrência de tiques, e até $60 \%$ dos pacientes com ST apresentam sintomas obsessivo-compulsivos (SOC), que se assemelham, mas, não necessariamente, caracterizam o TOC. A associação (comorbidade) da DT/ST com o TOC é uma complicação extra para o problema. O TOC, também, não possui etiologia, plenamente, conhecida e o que se tem a seu respeito se aproxima das hipóteses apresentadas para a DT/ST: genética, imunológica e neuroquímica. A hipótese genética, assim como para $\mathrm{DT} / \mathrm{ST}$, exige maiores esclarecimentos por meio do estudo de gêmeos idênticos em famílias biológicas e adotadas, já que a mera ocorrência hereditária ou familiar pode ser resultado de exposição ambiental semelhante. Entretanto, percebe-se uma maior prevalência da doença entre gêmeos idênticos (monozigóticos) que entre não idênticos (dizigóticos) e há, também, uma reconhecida correlação parental positiva entre ST, SOC e TOC, o que fornece indícios que podem corroborar a hipótese da existência de genes que determinam a susceptibilidade do indivíduo ao TOC. Nesse sentido, estão em andamento estudos que buscam identificar determinações genéticas relacionadas ao sistema serotonérgico e dopaminérgico e foi identificada uma correlação positiva entre a disfunção desses sistemas e o TOC. Foram, também, encontradas diferenças genéticas específicas entre pessoas com TOC e tique e pessoas com TOC sem tique, assim como uma correlação entre alterações da enzima catecol-o-metiltransferase (COMT) e a ocorrência de TOC em homens, mas não em mulheres. Há uma dependência genética entre o grau de recaptação do neurotransmissor serotonina e a eficiência da proteína responsável por isso (5HTT). Tendo sido já identificada a participação da serotonina no TOC, investigações estão sendo feitas para se identificar o padrão genético desse sistema relacionado com a doença (GONZÁLEZ, 1999; ROSÁRIO-CAMPOS e MERCADANTE, 2000; MERCADANTE et al., 2004).

Essa hipótese imunológica carece, ainda, de maior corroboração empírica. E a hipótese neuroquímica supõe a ideia de que o córtex orbito frontal cerebral seria bombardeado com impulsos originados de outra região chamada tálamo e que não teriam sido, adequadamente, filtrados pelo núcleo caudado. Isso causaria uma super excitação cerebral que impediria o indivíduo de descartar certas ideias que, como um eco, se tornariam recorrentes, 
insuportáveis e irresistíveis, silenciadas apenas por uma ação que as refletisse no mundo exterior ou por um ato mental recursivo. Em um indivíduo normal, tais ideias, simplesmente, se dissipariam sem maiores consequências, já que sua intensidade seria reduzida pela filtragem promovida pelo núcleo caudado. Os medicamentos inibidores da recaptação de serotonina (como a sertralina e a fluoxetina) são aqueles indicados para o tratamento, este sempre associado com psicoterapia e apoio familiar intenso. A comorbidade TOC-DT/ST ou a ineficiência dos inibidores da recaptação exigem o uso concomitante de neurolépticos, como o haloperidol (antagonistas da dopamina). O tratamento medicamentoso deve ter introdução imediata frente à gravidade dos sintomas, ao risco de suicídio ou a quadro depressivo intenso (ROSÁRIO-CAMPOS e MERCADANTE, 2000; MERCADANTE et al., 2004). É necessário ressaltar que, na comorbidade com TDAH, o uso de metilfenidato pode exacerbar a ocorrência dos tiques, apesar de algumas evidências em contrário quando associado com fluoxetina, que possui efeito benéfico na ST (PASSOS e LOPEZ, 2010).

O TOC modifica-se bastante quanto aos sintomas durante a vida do paciente e possui prevalência em crianças do sexo masculino. Variando daí em diante, conforme a faixa etária, com discreta prevalência na mulher adulta, em taxas próximas a $2-4 \%$ da população em geral, de forma heterogênea e dentro de um espectro obsessivo-compulsivo, que confere à doença características das mais sutis às mais severas, tendo a $\mathrm{DT} / \mathrm{ST}$ como um dos possíveis elementos dentro desse continuum (GONZALEZ, 1999; ROSÁRIO-CAMPOS e MERCADANTE, 2000). Na infância, as compulsões são mais frequentes que as obsessões, antecedendo estas, mas é necessário distinguir entre o que se caracteriza como TOC e aquilo que representa um comportamento natural da faixa etária. Crianças possuem rituais como um elemento formador de sua condição psicológica e personalidade, variando em tipo e intensidade conforme o ambiente e a idade (ROSÁRIO-CAMPOS e MERCADANTE, 2000). Por exemplo, até os 4 anos, a criança exige ou executa alguns comportamentos replicantes, como a repetição de uma estória ou brincadeira, a organização compulsiva de coisas e a necessidade de um objeto específico para dormir, sem que isso se caracterize como TOC. Da mesma forma ocorre em outras faixas etárias, quando aos 6 anos as regras dos jogos passam a ter caráter quase irrevogável e os mais variados tipos de objetos podem se tornar foco do desejo de posse em coleções. Sem limites rígidos e obrigatórios quanto ao início e ao término de comportamentos característicos, crianças possuem um perfil comportamental mais ou menos semelhante nas diferentes faixas etárias e que se traduzem por meio de brincadeiras (VIGOTSKI, 2008), o que se constitui em importante informação para o diagnóstico diferencial do TOC nessa fase. Para tanto, é necessário considerar-se, ainda, a frequência, a intensidade e o sofrimento causados durante o dia, bem como o grau de interferência nas atividades diárias, a duração do comportamento ao longo do dia (pelo menos uma hora) e o tempo de existência e permanência dos sintomas.

Comportamentos repetitivos são parte integrante das estratégias pessoais para otimização da eficiência social e controle do ambiente e da imprevisibilidade dos acontecimentos. Contudo passam a se constituir em elemento patológico na medida em que assumem um caráter de importância acima do esperado na vida da criança, condicionando suas ações de maneira excessiva, ou extrapolam a faixa etária de sua ocorrência normal, perdendo qualquer sentido prático sobre o desempenho do indivíduo. Dessa forma, a sintomatologia se divide em algumas categorias básicas mais comuns, cujas denominações indicam sua relação com temas, como desejo de agressão, medo de acidentes, necessidade de simetria, limpeza e coleção e fixação em elementos religiosos e sexuais, associados ou não com DT/ST. Há uma associação frequente da DT/ST com o primeiro e com o último tema e com sintomas tic-like, podendo, em qualquer caso, haver sobreposição entre cada um deles e a existência de sintomas pouco frequentes não acolhidos ou descritos por tais temas. Uma diferenciação importante deve ser realizada entre ideia obsessiva, presente no TOC, e ideia delirante, característica de algumas psicoses. A primeira é claramente percebida pelo sujeito como inadequada (caráter ergodistônico), a segunda não goza dessa prerrogativa (caráter ergossintônico), mas, durante a infância, tal diagnóstico é dificultado pela incapacidade da criança em discriminar entre uma e outra ou de expressar essa diferença (GONZALEZ, 1999; ROSÁRIO-CAMPOS e MERCADANTE, 2000). Outra distinção importante deve ser realizada entre a origem das perturbações da DT/ST e do TOC, que em certas condições podem confundir o diagnóstico. A primeira é motivada por tensões físicas transitórias recorrentes em partes específicas do corpo, a segunda surge em resposta a preocupações persistentes que encaminham comportamentos complexos. Entretanto, ambas se materializam na tentativa de conferir alívio, ainda que temporário, ao indivíduo (MERCADANTE et al., 2004; RAMALHO et al., 2008).

\section{ENQUANTO ISSO, NA SALA DE AULA...}

Tic-toc, tic-toc, tic-toc... essa bem poderia ser a metáfora onomatopeica para quem sofre de DT/ST. O espaço de tempo entre um episódio e outro do tique 
nervoso acaba sendo um martírio medido em segundos se o indivíduo se encontra em uma situação na qual sua ocorrência pode lhe causar constrangimento. E não é surpresa para ninguém o fato de que a sala de aula, particularmente, para a criança e para o adolescente, é um espaço de grande tensão no que diz respeito às relações sociais. Qualquer desvio da norma aceita pelos pares pode se tornar motivo para o, hoje chamado, bullying. Apenas quem já sofreu algum tipo de assédio moral e físico na escola possui plena noção de quão constrangedora pode ser essa situação e o quanto isso é capaz de comprometer a autoestima e reduzir as oportunidades de socialização. Ainda que, por um lado, um assédio dessa natureza possa se caracterizar como um elemento do ambiente capaz de motivar defesas pessoais contra as adversidades futuras na vida adulta, tornando o indivíduo maduro e resistente à crítica alheia; por outro, se em doses cavalares em um período em que tais defesas estão, ainda, por se constituir, ele pode se tornar um obstáculo ao alcance da maturidade e de uma autoestima saudável, podendo calar tão fundo na alma do indivíduo que este passa a se perceber apenas pelos olhos do assediador e como uma pessoa menor do que realmente é (ALBUQUERQUE, WILLIAMS e D'AFFONSECA, 2013). Nesse aspecto, a DT, a ST e o TOC, especialmente, quando associados e manifestos na sala de aula sem o devido apoio e compreensão por parte do corpo docente, para que o aluno não se sinta excluído, pode se tornar um elemento adicional de estresse e ansiedade em um ambiente já suficientemente estressante e motivar situações de bullying (AINSCOW, 1998; AZENHA, RODRIGUES e GALVÃO, 2012).

Além da tensão que pode surgir entre o indivíduo acometido pela DT/ST e seus pares e do estado emocional daí decorrente, por si, comprometedor da aprendizagem possível, uma dispersão adicional da atenção na aula pode se dar pela frustrante tentativa de reprimir os episódios clônicos, contribuindo, assim, para as dificuldades de aprendizagem. A sala de aula é um lugar de enorme diversidade, o que inclui diferentes modos ou capacidades de aprender, e o portador da DT/ST emerge como mais uma diversidade a se considerar. Não basta a todas as crianças estarem na escola, é necessário que esse acesso seja de qualidade e encontre uma educação comprometida com a aprendizagem e com a formação do cidadão. Não cabe divinizar o portador de qualquer deficiência, como faziam os antigos egípcios, nem sacrificá-los, como os gregos e romanos da antiguidade, queimá-los em fogueiras, como se possuídos por demônios, ou segregálos em asilos fora das cidades, como faziam os medievais (PAULO, 2010). Evidentemente, qualquer cidadão contemporâneo seria avesso a práticas tão extremistas, contudo o que não se percebe é que tais condutas estão, em alguma medida, veladas e travestidas em práticas sociais excludentes, seja no sentido da divinização, que conduz à sua infantilização (superproteção familiar ou salas de educação especial, por exemplo), seja no sentido da demonização, que leva ao seu sacrifício (ausência de métodos pedagógicos adequados à diversidade, na qual essa população precisa ser considerada, por exemplo). É nesse sentido que o presente artigo se torna relevante. Muito se tem escrito sobre o assunto, mas nem tanto se fala sobre suas repercussões na escola e menos ainda se escreve de forma direcionada para professores em geral (PAULO, 2010), sem se reter em dados estatísticos ou em linguagem técnica do âmbito da Saúde, o que torna o texto, muitas vezes, incompreensível ou desinteressante para quem não é dessa área.

As discussões sobre DT/ST precisam estar inseridas no debate sobre a Educação Inclusiva, uma vez que se mostra um elemento comprometedor da aprendizagem e socialização do indivíduo na escola. Não basta ser abordada pela perspectiva da Educação Especial. Esta possui suas origens na segunda metade do século XVIII, quando foram criadas duas escolas especiais, uma para surdos e outra para cegos em Paris. Daí ao século XX, a ideia de criação de espaços especializados na educação de indivíduos com necessidades especiais (INE) proliferou e os interesses e diagnósticos da classe médica sobre os INEs é que orientaram os processos educativos no interior das escolas ou em salas especiais com currículo próprio. Tendo por base um parâmetro de normalidade, os indivíduos eram segregados de seus pares normais por meio dos diagnósticos e tratados como especiais por psicólogos e educadores. Em meados do século XX, passou-se a adotar o princípio da integração, pelo qual os INEs passaram a frequentar as escolas regulares, as quais não possuíam o preparo necessário para acolhê-los em suas necessidades. Nessa realidade, a escola tratava homogeneamente a todos e acabava por potencializar as diferenças, especialmente, entre os alunos normais e os não normais, e multiplicar os casos de insucesso escolar. $\mathrm{Na}$ tentativa de superar esse problema, profissionais de Educação Especial passaram a integrar o ambiente escolar regular para atendimento individualizado, o que não surtiu o efeito esperado e exigiu novas mudanças que vieram na forma da criação de condições especiais no interior das próprias salas regulares. Em finais do século $\mathrm{XX}$, o princípio da integração passou a ser contestado por sua ineficiência e a escola começou a constituir-se em torno do conceito de inclusão. Este previa uma educação na qual as especificidades de todos, e não apenas dos INEs, deveriam ser atendidas, independentemente de quaisquer dificuldades ou diferenças que eles pudessem ter, de forma que o indivíduo, mais que presença física na escola, pudesse ter um sentimento de pertença e de acolhimento, a escola assumindo a responsabilidade por 
ele e entendendo o processo educativo como cooperativo, no qual o sucesso individual é responsabilidade de todos e a diversidade é a regra (ONU, 1994; AINSCOW, 1998; SANCHES e TEODORO, 2006; FRAGOSO e CASAL, 2012). Nesse sentido, é o sistema que busca se ajustar à diversidade e não a diversidade que passa a ser, artificialmente, suprimida ao se exigir do indivíduo seu ajustamento (e consequente aviltamento) em nome de um padrão arbitrário de normalidade. Tal padrão de normalidade é resultado da dificuldade em se acolher as múltiplas ontologias relativas ao objeto de análise e está relacionada com a exclusão de parte significativa da população dos debates decisórios sobre as políticas públicas, população essa composta, inclusive, por INEs (MOL, 2007).

Nesse contexto, o indivíduo portador de DT/ST se beneficia, imensamente, do conceito de educação inclusiva, pois suas dificuldades de socialização, organização e aprendizagem são atenuadas por processos pedagógicos. E estes se constituem a partir da cooperação, do compartilhamento de responsabilidades e decisões, da valorização da diversidade, do desenvolvimento de competências sociais e da autonomia pessoal, da solução colaborativa de problemas, do clima encorajador, do ambiente amigo, da constituição coletiva de regras e de um currículo flexível, interdisciplinar e contextualizado, havendo uma participação multiprofissional e a integração dos pais na vida escolar. Contudo, em um ambiente no qual o fazer pedagógico segue linhas tradicionais e existe uma ignorância latente do corpo docente sobre as intercorrências características da DT/ST e de como lidar estrategicamente com elas, o ambiente se torna demasiadamente hostil, e o fracasso escolar de seu portador se apresenta como um futuro bastante provável (PAULO, 2010).

Como parte das estratégias pedagógicas que podem auxiliar o aluno no controle de seu problema e facilitarlhe a aprendizagem, existe a orientação aos colegas, funcionários e professores da escola sobre a situação; a organização do espaço de aula de forma acolhedora; a atitude positiva do professor; o estabelecimento de vínculo de confiança entre professor e aluno; a flexibilidade de trânsito do aluno para o exterior da sala; o privilégio à expressão escrita para quem possui dificuldades de expressão oral e vice-versa; a explicação passo a passo de tarefas a serem executadas e a confirmação do entendimento; a identificação das dificuldades de conclusão de trabalhos em decorrência de problemas viso-motores e de sintomas obsessivo-compulsivos, como a reescrita e releitura cíclicas; a tolerância com as intercorrências cíclicas; a paciência com episódios de raiva e o posterior diálogo sobre o ocorrido e sobre as formas de atenuar episódios futuros; a proposta de substituição de um tique por outro menos proeminente e o reforço positivo para isso e para o cumprimento de tarefas; o uso de técnicas de relaxamento e a criação de instrumentos de registro da frequência dos tiques para automonitoração e estabelecimento de metas de controle. Estratégias possíveis de se estabelecer em parceria com os colegas de sala, com os pais e com o próprio portador da DT/ST. Estas, devedoras de uma percepção ampliada e humanizada de educação, possuem grandes chances de atenuar o sofrimento do aluno e garantir-lhe sucesso em seus afazeres (RAMALHO et al., 2008).

\section{CONSIDERAÇÕES FINAIS}

O presente artigo busca apresentar a DT/ST e o TOC, realizando uma revisão do tema e explicitando algumas de suas características fisiopatológicas e seus aspectos sociais e pedagógicos, com o objetivo de contribuir com a informação, principalmente, de professores sobre o assunto, a fim de que ambas possam ser mais bem trabalhadas no interior da escola, em benefício do aluno portador. Assim, ressalta-se que tais patologias possuem incidência relativamente alta de comorbidade e que, muitas vezes, caso o diagnóstico não seja bem estabelecido, pode haver confusão entre a sintomatologia da DT/ST e a do TOC. Também se conclui que a DT/ST, considerada no passado medieval indicador de possessão demoníaca, é hoje compreendida como uma disfunção do SNC, com etiologia genética e que, apesar do grande avanço dos estudos, desde 1825 , ainda não se tem clareza sobre seus mecanismos e formas de tratamento eficiente.

A comorbidade DT/ST-TOC é um complicador extra, tanto para a vida cotidiana quanto escolar do indivíduo acometido e daqueles que o rodeiam, demandando estratégias variadas para que o sofrimento e os reveses na vida deste, que é percebido como um INE, sejam reduzidos. Tais estratégias variam desde terapias comportamentais a tratamentos farmacológicos, passando pelas necessárias estratégias familiares e pedagógicas, sem as quais quaisquer outras surtiriam efeitos quase risíveis. Diante da importância da escola na mitigação do sofrimento e potencialização da aprendizagem e da socialização da criança ou adolescente acometido pela $\mathrm{DT} / \mathrm{ST}$, cursos de qualificação, material educativo e artigos científicos dirigidos a seus atores tornam-se uma necessidade premente e que ainda, não foi plenamente atendida.

Buscamos suporte na literatura e na prática referente à Educação Inclusiva. O conceito de inclusão, mais que o de integração, visa a tratar os problemas que acometem aqueles possuidores de necessidades especiais pela perspectiva da singularidade inerente ao ser humano, em 
uma abordagem que se opõe à pretensa homogeneidade proposta por modelos tradicionais e conservadores de educação. Nesse aspecto, a heterogeneidade, e não a homogeneidade, torna-se o padrão e o que era, anteriormente, considerado um desvio da norma, um problema a ser tratado de modo particular, passa a integrar o largo espectro da diversidade humana, dentro do qual se encontram a DT/ST e o TOC. Assim, todos os alunos passam a ser percebidos como pessoas especiais e merecedores de certo grau de individualização no atendimento pedagógico, conforme sua própria especificidade e independentemente de diagnósticos médicos que, muitas vezes, mais estigmatizam que contribuem para a superação do problema.

Infelizmente, muito ainda se precisa caminhar na direção da institucionalização de um modelo de escola que, realmente, seja capaz de atender às diretrizes de uma Educação Inclusiva. A perspectiva da inclusão exige não apenas o esforço isolado de algumas instituições ou profissionais comprometidos com a causa, mas sim o engajamento, por parte dos formadores de políticas públicas e tomadores de decisão, e seu esforço sincero na constituição de intervenções e na destinação de verbas para adequação dos recursos humanos, materiais e físicos necessários. O que se vê hoje, principalmente nas escolas públicas, são as boas intenções e o orçamento escoando pelas brechas, quando não, literalmente, das próprias paredes e muros carcomidos pela falta de manutenção das estruturas administrativas e teóricas da escola. Ambiente que é submetido às exigências de uma Educação Inclusiva com suas salas de aula abarrotadas, estrutura física tradicional, contingente insuficiente e professores despreparados para o acolhimento eficiente da diversidade.

Para finalizar, aos que se interessarem em buscar maiores informações sobre DT/ST e TOC, fica a indicação da Associação Brasileira de Síndrome de Tourette, Tiques e Transtorno Obsessivo-Compulsivo (Astoc), fundada em São Paulo, em 1996, e acessível no endereço http://www. astoc.org.br, cujo objetivo gira em torno da informação, suporte e orientação a pacientes, profissionais e instituições que queiram lidar com a doença, inclusive por meio de um fundo de apoio à pesquisa.

\section{REFERÊNCIAS}

AINSCOW, Mel. Necessidades especiais na sala de aula. Um guia para a formação de professores. Lisboa: Instituto de Inovação Educacional/Edições Unesco, 1998.

ALBUQUERQUE, Paloma Pegolo de; WILLIAS, Lúcia Cavalcanti de Albuquerque; D'AFFONSECA, Sabrina Mazo. Efeitos tardios do bullying e transtorno de estresse póstraumático: uma revisão crítica. Psic.: Teor. e Pesq., v. 29, n. 1, p. $91-98,2013$.
AZENHA, Margarida Rita de Jesus; RODRIGUES, Sandra Maria Antunes; GALVÃO, Dulce Maria Pereira Garcia. Bullying e a criança com doença crônica. Rev. Enf. Ref., v. III, n. 6, p. 45-53, 2012.

DIAS, Fernando M.V.; KUMMER, Arthur; HOUNIE, Ana Gabriela; TEIXEIRA, Antônio L. Neurobiologia da síndrome de Tourette: a hipótese autoimune pós-estreptocócica. Rev. Psiq. Clín., v. 35, n. 6, p. 228-235, 2008.

FERRARO, L. I.; RIBEIRO, K. F. V. S.; CAVALHEIRO, L. G. Avaliação da fluência da fala em um paciente com síndrome de Gilles de La Tourette. Rev. Pró-Fon., v. 20, p. 1-3, 2008.

FRAGOSO, Francisca M. Rocha Almas; CASAL, João. Representações sociais dos educadores de infância e a inclusão de alunos com necessidades educativas especiais. Rev. Bras. Educ. Espec., v. 18, n. 3, p. 527-546, 2012. Disponível em: $<$ http://www.scielo.br/pdf/rbee/v18n3/a11.pdf $>$. Acesso em: 15 jan. 2015.

FREIRE, Paulo. Pedagogia do oprimido. 17 ed. Rio de Janeiro: Paz e Terra, 1987.

GERMINIANI, Francisco; MIRANDA, Ana Paula; FERENCZY, Peter; MUNHOZ, Renato; TEIVE, Hélio. Tourette's syndrome: from demonic possession and psychoanalysis to the discovery of genes. Arq. Neuropsiq., v. 70, n. 7, p. 547-549, 2012.

GONZALEZ, Christina Hajaj. Transtorno obsessivocompulsivo. Rev. Bras. Psiq., Genética, v. 21, p. 29-32, 1999.

HOUNIE, Ana; PETRIBÚ, Kátia. Síndrome de Tourette: revisão bibliográfica e relato de casos. Rev. Bras. Psiq., v. 21, n. 1, p. 50-63, 1999.

LOUREIRO, Natália L. V.; MATHEUS-GUIMARÃES, Cecília; SANTOS, Dilvani O.; FABRI, Roberto G. F.; RODRIGUES, Carlos R.; CASTRO, Helena C. Tourette: por dentro da síndrome. Rev. Psiq. Clín., v. 32, n. 4, p. 218-230, 2005.

MATTOS, James P.; MATTOS, Vânia MBC. Doença dos tiques: aspectos genéticos e neuroquímicos atuais. Arq. Neuropsiq., v. 57, n. 2-B, p. 528-530, 1999.

MERCADANTE, Marcos T.; ROSARIO-CAMPOS, Maria C.; QUARANTINE, Lucas C.; SATO, Fábio P. As bases neurobiológicas do transtorno obsessivo-compulsivo e da síndrome de Tourette. Jornal de Pediatria, v. 80, n. 2 (supl.), 2004.

MOL, Annemarie. Política ontológica: algumas ideias e várias perguntas. In: NUNES, João Arriscado e ROQUE, Ricardo (Org.). Objectos impuros: experiências em estudos sociais da ciência. Trad. Gonçalo Praça. Porto: Edições Afrontamento, 2007.

ONU - Organização das Nações Unidas. A/RES/48/96. Declaração de Salamanca: Sobre Princípios, Políticas e Práticas na Área das Necessidades Educativas Especiais. Conferência Mundial de Educação Especial. 07-10/jun. Unesco, 1994. Disponível em: <http://portal.mec.gov.br/seesp/arquivos/pdf/ salamanca.pdf>. Acesso em: 15 jan. 2015.

PASSOS, Roberta Benitez Freitas; LOPEZ, José Ramón Rodriguez Arras. Síndrome de Gilles de la Tourette associada ao transtorno de déficit de atenção com hiperatividade: resposta clínica satisfatória a inibidor seletivo da recaptura de serotonina e metilfenidato. J. Bras. Psiq., v. 59, n. 2, p. $160-162,2010$. 
PAULO, Elisabete dos Santos. Síndrome de Gilles de La Tourette: intervenção educativa em interacção inclusiva, 212 p. Dissertação (Mestrado em Educação Especial no Domínio Cognitivo e Motor) - Programa do Instituto de Ciências da Educação. Universidade Lusófona de Humanidades e Tecnologias. Lisboa/PT, 2010. Disponível em: <http://recil. grupolusofona.pt/bitstream/handle/10437/1228/Volume\%201. pdf? sequence $=1>$. Acesso em: 15 jan. 2015 .

RAMALHO, Joaquim; MATEUS, Filipa; SOUTO, Marisa; MONTEIRO, Marlene. Intervenção educativa na perturbação de Gilles de la Tourette. Rev. Bras. Educ. Esp., v. 14, n. 3, p. 337-346, 2008. Disponível em: <http://www.scielo.br/pdf/ rbee/v14n3/v14n3a02.pdf>. Acesso em: 15 jan. 2015.

REINHARDT, Marcelo C.; REINHARDT, Caciane A. U. Transtorno de déficit de atenção/hiperatividade, comorbidades e situações de risco. J. Pediatr., Rio de Janeiro, v. 89, n. 2, p. 124-130, 2013.

ROSARIO-CAMPOS, Maria Conceição; MERCADANTE, Marcos T. Transtorno obsessivo-compulsivo. Rev. Bras. Psiq., v. 22, supl. II, p. 16-19, 2000.
SANCHES, Isabel; TEODORO, António. Da integração à inclusão escolar: cruzando perspectivas e conceitos. Rev. Lusófona de Educação, n. 8, p. 63-83, 2006. Disponível em: $<$ http://www.scielo.gpeari.mctes.pt/pdf/rle/n8/n8a05.pdf $>$. Acesso em: 15 jan. 2015].

SANZ, Maria Jesús M. Transtornos de tics: el síndrome de Gilles de la Tourette. In: Psiquiatría del niño y del adolescente: método, fundamentos e syndromes. Madrid: Díaz de Santos, 1994. p. 545-570.

VÁZQUEZ-PALACIOS, G; BONILLA-JAIME, H. Nicotine acetylcholine receptors and neuropsychiatric disorders. Rev. Neurol., v. 39, n. 12, p. 1146-1160, 2004. Disponível em: $<$ http://www.ncbi.nlm.nih.gov/pubmed/15625635>. Acesso em: 15 jan. 2015.

VIGOTISKI, Levi Semenovich. A brincadeira e o seu papel no desenvolvimento psíquico da criança. Rev. Virtual de Gestão de Iniciativas Sociais, n. 8, p. 23-36, 2008.

Recebido em 05-10-2016.

Aprovado em 09-03-2017. 